\title{
NAÇÃO E UTOPIA EM A JANGADA DE PEDRA E O FEITIÇO DA ILHA DO PAVÃO
}

Marco Antonio Rodrigues

\section{RESUMO:}

O artigo propõe uma leitura comparativa sobre os temas "nação" e "utopia" em dois romances contemporâneos de língua portuguesa: $A$ jangada de pedra (1986), de José Saramago, e O Feitiço da Ilha do Pavão (1997), de João Ubaldo Ribeiro. A análise baseia-se em conceitos de Fredric Jameson sobre a utopia na pós-modernidade, e na aproximação entre o mecanismo utópico e a nação como "comunidade imaginada", de Benedict Anderson. A conclusão destaca que, mesmo recorrendo ao fantástico, ao sobrenatural, as utopias de Saramago e de João Ubaldo são acanhadas, e que, como propõe Jameson, talvez não haja mais espaço para a utopia na contemporaneidade.

\section{PALAVRAS-CHAVE:}

Nação; utopia; José Saramago; João Ubaldo Ribeiro; Fredric Jameson.

\section{Introdução}

Este artigo propõe uma leitura comparativa sobre os temas "nação" e "utopia" em dois romances contemporâneos de língua portuguesa: $A$ jangada de pedra, de José Saramago, e O Feitiço da llha do Pavão, de João Ubaldo Ribeiro.

Para esboçar o entendimento da utopia no contexto da pós-modernidade, contexto em que as obras de Saramago e João Ubaldo foram produzidas, será útil resgatar as formulações de um dos principais pensadores do (e sobre o) período, curiosamente também um dos que mais têm se dedicado à questão da utopia em tempos atuais, Fredric Jameson. Especificamente, serão retomados conceitos expressos no artigo "A política da utopia" (JAMESON, 2006), em que o autor sumariza seu entendimento a respeito do tema na contemporaneidade.

O primeiro desses conceitos é sobre o caráter constructo da utopia, quase que exercício de bricolagem. O segundo deles refere-se à observação de que a produção utópica de diferentes períodos sempre esteve associada a momentos de crise de valores. O terceiro elemento refere-se ao caráter ideológico da utopia. E, por último, a mais controversa das proposições de Jameson, sobre a função negativa da utopia, nosso confinamento em um presente não-utópico sem historicidade nem futuridade. Em outras palavras, nossa incapacidade de imaginar um mundo melhor. 


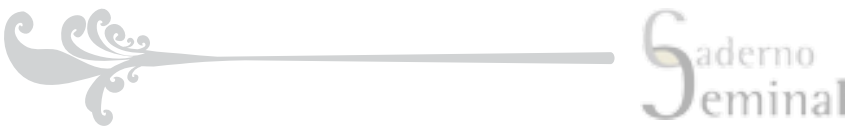

A palavra Utopia, cunhada por Thomas More na obra homônima publicada em 1516, funde o advérbio grego ou (não) ao substantivo tópos (lugar) - não lugar, "o que está em nenhum lugar". A obra de More trata, porém, de um tema - a melhor constituição de uma República - já presente em Platão e Aristóteles. (LOGAN e ADAMS, 2009, p. XXVII) More inova na adoção do relato fictício sobre a utopia, inaugurando uma temática de grande recorrência na abordagem literária.

Na construção ficcional, a ilha é vista como espaço privilegiado para a utopia, a começar pela ilha de More. Se não a ilha propriamente dita, a situação de insulamento, de isolamento:

A utopia é sempre isolada da nossa história, mesmo quando não é uma ilha: a Cidade do Sol de Campanella, por exemplo, fica "numa vasta planície situada sob o Equador". Tal insularismo não é apenas uma ficção geográfica: é uma atitude mental da qual a ilha clássica é apenas a representação, responde à exigência de preservar a comunidade da corrupção externa e de apresentar um mundo fechado, um microcosmo no qual existam leis específicas que escapam ao campo magnético do real. (BERRIEL et. all. 2008, p. 5)

Centrada na especulação sobre um não-lugar, a utopia é, porém, vinculada a uma localidade e um tempo historicamente determinados. É, nesse sentido, datada, por fornecer respostas a problemas contemporâneos à sua elaboração. Por consequência, a utopia é também ideológica, é "transmitida e expressa a partir da experiência social do pensador utópico, a qual só pode ser uma experiência de classe e refletir o ponto de vista de uma classe específica sobre a sociedade" (JAMESON, 2006, p. 172). Decorre dessa historicidade e desse ponto de vista de classe que a análise literária de narrativas de caráter utópico dificilmente poderá prescindir de elementos contextuais, sem grandes prejuízos para a interpretação.

\section{Utopia e nação}

Mantidas as ressalvas de Paulo Arantes (2006, p.28) quanto à motivação "material" do surgimento das nações, parece bastante óbvia a proximidade entre a definição de Benedict Anderson (2008), da nação como "comunidade imaginada", e o mecanismo da utopia tal como sumarizado até aqui. A utopia nasce da especulação sobre a melhor constituição da República; como metáfora pseudo-geográfica em espaço delimitado, assume frequentemente a forma de país hipotético, com população, leis e instituições próprias. A nação, por sua vez, ao congregar sujeitos que sequer se conhecem em torno de uma ideia comum, não deixa de ser em certo sentido uma utopia, cuja expressão mais evidente é seu "hino nacional".

A utopia, porém, é uma construção que não tem seu nexo fixado a partir de experiências como as relatadas por Anderson no processo de "imaginação" de uma nação, como o trânsito e intercâmbio de funcionários peregrinos e a 


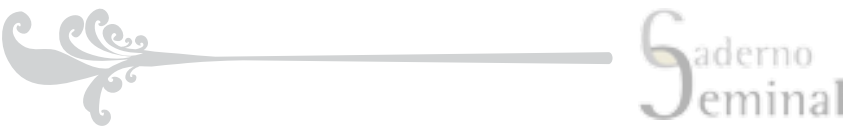

troca de experiências pela leitura de jornais e do romance. Ela é construção fabular que contribui no processo de formação e formalização das nações. Jameson (2006, p. 165) identifica a "constituição" como gênero ou tipo de discurso correlato à utopia.

No contexto deste artigo, interessa descrever e comentar, ainda que brevemente, como os utopistas ocasionais José Saramago e João Ubaldo reconstroem (ou desconstroem) literariamente as suas nações, diretamente representadas nos romances $A$ jangada de pedra e $O$ feitiço da Ilha do Pavão.

\section{Saramago - da inutilidade da palavra "utopia"}

Em sua participação no Fórum Social Mundial - 2005, em Porto Alegre - RS, José Saramago, ao tratar do tema "Quixotes hoje: utopia e política"1, foi no mínimo provocativo ao sugerir que a palavra "utopia" deveria ser eliminada do dicionário.

É preciso interpretar com reserva a fala de Saramago, já que ela é dirigida para uma plateia específica de "quixotes", como em um comício. O momento e o contexto eram propícios a palavras de ordem, a sugestões de novos rumos para uma esquerda desconcertada. É para esse público que Saramago anuncia, logo ao início de sua palestra: "Tenho uma má notícia para vos dar: eu não sou utopista. E pior notícia ainda: considero a utopia, ou o conceito utopia, não só inútil, como também tão negativo como a ideia de que quando morremos todos iremos para o paraíso".

O argumento de Saramago é simples, por isso mesmo cativante: para o autor, projetamos a utopia em um futuro que não nos será acessível; um futuro talvez acessivel somente a novas gerações, para as quais o necessário atual não mais o será. A utopia se configura assim, para o romancista português, como o "discurso sobre o não existente", já que as palavras, "essas desgraçadas", sempre estão a mudar de sentido. Se as utopias fossem projetadas para o dia de amanhã, iríamos alcançando-as em curto prazo e elas não se chamariam mais utopia, mas apenas "trabalho".

Saramago faz, portanto, a defesa do pragmatismo na luta pela igualdade e justiça, mas é difícil não pensar em desdobramentos contraditórios entre esse posicionamento e sua ficção, ou mesmo sua atividade política. É que, para Saramago, o problema está mais na palavra "utopia" que nas posições e ações que ela suscita. $A$ jangada de pedra é um desses registros ficcionais de Saramago que guardam estreitas relações com o gênero utópico, como já tratado em diversas leituras acadêmicas².

$1 \quad$ O vídeo da palestra de Saramago está disponível em

http://www.youtube.com/watch?v=yh2GDMzdMBE\&feature=related Acesso em: 07/11/2011.

2 A respeito da utopia em A jangada de Pedra, ver, por exemplo, Martins (2004), Rocha (2009) e Penha (2004). 


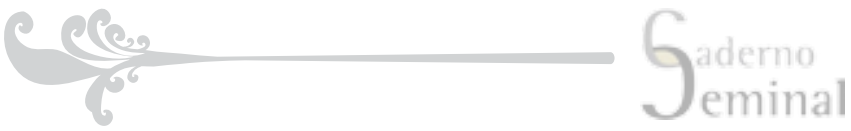

A obra é de 1986; anterior, portanto, à queda do Muro de Berlim e ano da inclusão de Portugal e Espanha na União Europeia. Duas utopias do mundo político, uma em decadência, outra em ascensão. O autor, Saramago, não era indiferente a nenhuma delas: "comunista hormonal", como se autodefiniu em certa ocasião, o autor era também bastante cético quanto às perspectivas de Portugal na União Europeia. Uma década após a publicação de $A$ Jangada de pedra, em visita ao Brasil para receber o Prêmio Camões, Saramago profere a palestra intitulada "Portugal - Fim de milênio, princípio de quê?"3 Nada mais esclarecedor de seu posicionamento a respeito da União Européia do que a passagem a seguir:

Historicamente, aquilo que sempre esteve em causa na Europa - a disputa,
pelas nações mais poderosas, da hegemonia sobre o continente-está hoje
sendo orientado no sentido duma definição de soluções e métodos que,
apresentando-se como qualitativamente novos, permitam chegar a idêntico
resultado quantitativo, sem ter de recorrer pela milésima vez à guerra como
a ultima ratio, por esse modo se instituindo uma concentração de poder
que, aparentemente consubstanciada numa comunidade de povos, é, na
realidade, administrada de facto por alguns países dessa mesma comunidade,
precisamente, mas não por acaso (oh, ironia), aqueles que, até ao passado
mais recente, foram os actores directos ou os promotores indirectos das
terríveis lutas que, ao longo dos séculos, e sob os mais diferentes pretextos,
cobriram de mortos e de ruínas o continente europeu. (SARAMAGO, 1996)

Essa denúncia da falsa comunhão europeia, pela qual não só os países ibéricos, mas principalmente Grécia e Itália hoje pagam caro, parece ter sido mesmo um dos mastros principais dessa jangada que, ao desprender-se fisicamente do continente europeu, retoma o destino navegante de seus ocupantes, não com a antiga ambição da descoberta do Eldorado, mas simplesmente à deriva, numa busca involuntária de melhor posicionamento no concerto das nações.

\section{Um socialismo espontâneo em $\boldsymbol{A}$ jangada?}

O argumento de $A$ jangada de pedra é bastante conhecido: sem que haja qualquer explicação plausível para o fato, a Península Ibérica destaca-se (melhor dizer "descola-se") da Europa, bem na junção dos Pirineus, e passa a vagar pelo Oceano Atlântico em velocidade regular e aparentemente sem rumo definido. Hipoteticamente relacionados ao grande fato, acontecimentos banais, tratados, porém, como obscuros, acabam por unir o grupo que protagoniza a narrativa: Joana Carda risca o chão com uma vara de negrilho, o que "faz" ladrarem os cães mudos de Cérbere (na França); Joaquim Sassa, um funcionário de escritório, lança ao mar, a uma grande distância, uma pedra que mal deveria poder suster; o espanhol Pedro Orce, farmacêutico, sente a terra tremer, intermitentemente; o professor José Anaiço é acompanhado, em qualquer parte aonde vá, por uma grande revoada de estorninhos; Maria Guavaira, espanhola como Orce, desfaz uma meia, puxando um fio que nunca se finda; e o cão Ardent, remanescente

$3 \quad$ Citada por Eduardo Calbucci (1999). 
de Cérbere, salta o abismo da fenda formada inicialmente entre a França e a ex-península, optando pelas "regiões infernais" e vindo, mais adiante na narrativa, a servir de guia do grupo em suas aventuras.

Os efeitos imediatos da separação se desdobram em fenômenos sociais (a fuga em massa dos turistas, a ocupação dos hotéis de turismo por famílias sem posses, a desocupação do litoral, etc.), econômicos (a fuga do capital especulativo, junto com as pessoas de posse; a crise no abastecimento interno; a desvalorização da propriedade privada, principalmente os automóveis sem combustível) e políticos (a crise junto à União Europeia e a intervenção política dos Estados Unidos). Diante desses e outros fatos, as pessoas passam a cultivar valores mais simples, ligados à subsistência diária, enquanto esperam por uma definição de seus destinos. O grupo de protagonistas, cada qual a seu tempo, abandona seus lares, suas profissões e passa a se dedicar exclusivamente à jornada pelo território ibérico. De início, quando o número de viajantes ainda permite, cruzam o território de automóvel, para depois seguirem adiante em uma carroça. Vão, de Portugal à Espanha, à procura de Pedro Orce; rumam para o litoral, com o propósito de ver o rochedo de Gibraltar passar; retornam ao interior, seguem para Espanha, vão ao que restou dos Pirineus, observar o abismo, e retornam à Espanha, para o enterro de Pedro Orce.

No âmbito político, o governo português propõe e implanta a formação de um governo de salvação nacional, com a participação de todas as forças políticas (p. 184). A medida proposta pelo novo governo de desocupação do litoral pressupõe a mudança de grandes massas para o interior, a reaproximação dos lugares de origem e o apelo à solidariedade familiar do "onde comem dois, comem três". Já ao final da narrativa, a gravidez simultânea de todas as mulheres férteis da Península sugere o nascimento de uma nova geração, em uma nova sociedade, plantada no mesmo território, porém em outro contexto.

Todos esses desdobramentos sinalizam a volta aos valores e costumes de uma "época de ouro", espécie de socialismo espontâneo, não planejado, muito embora seja indispensável destacar que, em todos os casos relatados, a chave da narrativa é irônica. Ou seja, o anúncio de que "assim será" não significa que de fato tenha sido, e o narrador de Saramago é mestre no cinismo em passagens como:

A grande maioria, por que não dizê-lo, a maioria esmagadora dos habitantes de Lisboa não nasceram lá, e os que nela nasceram encontram-se ligados aqueles por laços familiares. As consequências de um tal facto são amplas e decisivas, sendo a primeira que uns e outros deverão transferir-se para os lugares de origem, onde, regra geral, ainda têm parentes, alguns mesmo que as circunstâncias da vida fizeram perder de vista, assim se aproveitando esta oportunidade forçada para reintroduzir a harmonia nas famílias, sanando-se antigos desentendimentos, ódios por heranças más e partilhas péssimas, rixas de mal-dizer, a grande infelicidade que nos cai em cima terá o mérito de aproximar os corações. (SARAMAGO, 2006, p. 193) 


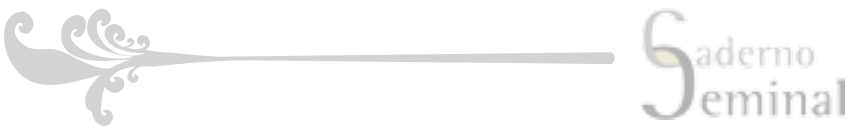

A mesma abordagem irônica servirá, logo adiante, para traçar um retrato oposto a esse, de harmonia e entendimento, desarmando, também, a expectativa do leitor quanto ao destino de uma utopia clássica:

Quem, por estar longe destes acontecimentos e lugares, imaginou que os retirantes ibéricos, amontoados em casas, asilos, hospitais, quartéis, armazéns, barracões, ou nas tendas e barracas de campanha que foi possível requisitar, mais as que foram cedidas e armadas pelos exércitos, e aquela outra gente, ainda mais numerosa, que não encontrou alojamento, e vive por aí debaixo das pontes, ao abrigo das árvores, dentro de automóveis abandonados, quando não ao puro relento, quem imaginou que Deus veio viver com estes anjos, saberá muito de anjos e de Deus, mas de homens não conhece nem a primeira letra. (SARAMAGO, 2006, p. 206)

Em seguida, descreve-se o inferno em terras flutuantes, sob o fundamento também irônico da crítica do narrador ao ponto de vista idealizante, maniqueísta, que enaltece os valores morais das classes baixas, em contraponto com o egoísmo e a ganância das elites, o que suscita "ódios e antipatias, a par desse mesquinho sentimento que é a inveja, fonte de todos os males" (p. 206). Ora, se a inveja fosse de fato a fonte de todos os males, ou a ganância, como é comum às utopias desde More, a construção utópica deveria orientar-se para a sua extinção ou seu pleno controle, o que nem de perto acontece à lbéria à deriva. Onde a utopia, então?

\section{Trans-iberismo na rota da jangada}

Portugal e Espanha se desprendem do continente e saem valsando oceano afora. Na Europa, não deixam saudades. Ao, num primeiro momento, tomarem o rumo da América do Norte, vêem-se alvos de uma cobiçosa diligência dos EUA em sua anexação ao território americano. Enquanto isso, na Europa, os jovens de diversos países saem às ruas a gritar "nós também somos ibéricos", como que a exercitar aleatoriamente a sua rebeldia. Nova orientação do movimento faz a jangada rumar para o Sul, deslizando entre a América Central e a África. Seu destino final permanece desconhecido, só se sabe que é essa sua orientação quando, já no desfecho do romance, o movimento se interrompe.

O trajeto da ilha é acompanhado à distância pela agitação política em diferentes partes do globo, em que os líderes mundiais especulam sobre as possíveis providências para o restabelecimento da harmonia entre as nações ocidentais. Essas especulações, por sua vez, são acompanhadas de perto por um anedotário de cunho nacionalista do tipo "se a Península lbérica se queria ir embora, então que fosse, o erro foi tê-la deixado entrar" (p. 38). Ou esta mais sutil: "E não foi da França que a península se separou, foi da Europa, parece a mesma coisa, mas faz a sua diferença". Ou, da parte dos britânicos, quando da afirmação do Parlamento quanto a sua soberania sobre Gibraltar: "O senhor primeiro-ministro 


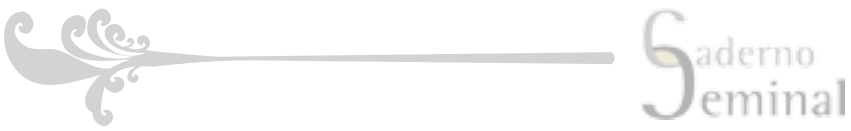

incorreu numa grave falta de precisão vocabular quando chamou península àquilo que já é hoje, sem qualquer dúvida, uma ilha, ainda que sem a firmeza da nossa, of course". (44)

Esse anedotário diz muito sobre o nacionalismo dos países europeus, mas o autor José Saramago teve, em vida, posições mais objetivas, por isso mesmo polêmicas, sobre a situação de Portugal e Europa no continente europeu. Sobre o assunto, o autor nos deixou um documento interessante, publicado em espanhol, quase que com instruções a respeito do tratamento que deveria merecer o tema "iberismo" em sua obra literária e em sua atuação política:

"cualquier identificación que se haga de mi trabajo literario o de mi intervención cívica y política con un cuerpo de doctrina, plan de acción o una estrategia que apunten al resurgimiento o a la reactivación de la cuestión ibérica tendrá que plegarse, o al menos no ignorar, los argumentos y precisiones aquí expresados." (SARAMAGO, 1990)

Inevitável acompanhar, ainda que à distância, seus argumentos a respeito. Para Saramago, qualquer português, antigo ou moderno, foi ou é instruído com a convicção de que a Espanha é seu "inimigo natural", o que teria ajudado a formar, a robustecer e a consolidar sua própria identidade nacional. Com o tempo, o interesse e contato direto com a Espanha teriam possibilitado a Saramago identificar as diversidades nacionais que emergiam da unidade estatal, o que, por sua vez, teria motivado a aspiração a uma nova relação, não entre os estados, mas um encontro contínuo entre as nacionalidades da Península, baseado na harmonização dos interesses, nos intercâmbios culturais, enfim, na intensificação do conhecimento (SARAMAGO, 1990).

De certa forma, a experiência vivenciada pelo grupo de protagonistas faz as vezes de "balão de ensaio" desse intercâmbio. O conhecimento de diferentes regiões e diferentes culturas ocorre simultaneamente ao conhecimento afetivo entre o grupo, tanto que em certo momento ele passa a figurar uma micro-utopia em viagem pelo território. Mas o argumento de Saramago em favor do iberismo não para por aí. 0 processo de re-conhecimento das "nacionalidades" espanholas teria sido frustrado pela adesão de Portugal e Espanha à União Europeia, e caberia ao homem desse tempo jurar à Europa, mesmo sem saber bem que Europa seria essa.

Desencantado com os fatos políticos, ao voltar sua atenção para a América, onde as pessoas seguem falando e escrevendo português e castelhano, o autor teria chegado à conclusão de que a própria Península Ibérica não poderá ser hoje plenamente entendida fora de sua relação histórica e cultural com os povos de ultramar (Saramago, 1990). A metáfora da jangada não deixa de ser também, pois, um gesto de vingança, a vingança possível para um escritor. Ao mesmo tempo, o trajeto da ilha indica o caminho a ser tomado pelos povos ibéricos, tanto que o narrador faz questão de substituir a palavra deriva por "navegação", na passagem abaixo: 
Ora, esses governos, em vez de nos apoiarem, como seria demonstração de elementar humanidade e duma consciência cultural efectivamente europeia, decidiram tornar-nos em bodes expiatórios das suas dificuldades internas, intimando-nos absurdamente a deter a deriva da península, ainda que, com mais propriedade e respeito pelos factos, lhe devessem ter chamado navegação. Esta atitude é tanto mais lamentável quanto é sabido que em cada hora que passa nos afastamos setecentos e cinquenta metros do que são agora as costas ocidentais da Europa, sendo que os governos europeus, que no passado nunca verdadeiramente mostraram querer-nos consigo, vêm agora intimar-nos a fazer o que no fundo não desejam e, ainda por cima, sabem não nos ser possível. (SARAMAGO, 2006, p. 146)

A defesa do intercâmbio cultural e da harmonização de interesses transcende, portanto, o espaço ibérico, abrangendo a América Latina e a África e motivando a nova expressão com a qual Saramago define seu posicionamento: trans-iberismo.

\section{A jangada de pedra e $O$ feitiço da llha do Pavão - exercício comparativo}

O exercício comparativo entre Jangada e Feitiço tem como pressuposto teórico, não uma gênese comum entre as obras, mas principalmente similaridades formais e temáticas, ou, na caracterização de Claudio Guillén (2005), processos que implicam "condições socio-históricas comuns". Compartilhando, as obras, da mesma língua de expressão e contando com um hiato de uma década entre o surgimento de uma e outra, não seria motivo de surpresa a leitura e o conhecimento prévio de João Ubaldo Ribeiro sobre $A$ Jangada de Pedra. No entanto, não se percebem referências explícitas no romance do autor brasileiro ao texto que o antecede.

Essa ausência de uma gênese comum explícita, se bem observada, não inviabiliza ou diminui a validade do exercício comparativo, tendo em vista ser a cada dia mais aceito em literatura comparada o estudo não genético de categorias supranacionais (GUILLÉN, 2005, p. 115). No contexto deste artigo, são categorias supranacionais os elementos formais e temáticos que aproximam as obras da narrativa utópica, bem como o próprio conceito de "nação" por elas problematizado.

\section{Utopia e construção}

Uma das similaridades formais entre as obras está na construção do foco narrativo. Na tipologia de Norman Friedman, sumarizada por Ligia Chiappini (1985), tanto o narrador de Saramago como o de João Ubaldo se aproximam do que caracteriza o narrador onisciente intruso, sendo o de Saramago mais explicitamente digressivo. As características de intrusão e digressão contribuem para o tom satírico de ambas as narrativas, estando a narrativa de Saramago mais próxima da sátira intelectual de Swift (sátira ao gênero utópico), e a de João Ubaldo mais familiarizada com a narrativa rabelaisiana (dessacralizadora, "baixo ventre"). A sátira, por sua vez, distancia as obras de uma idealização utópica nos moldes tradicionais. 


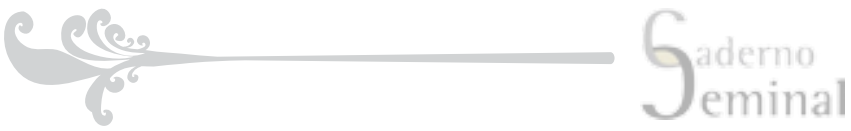

No que se refere à ambientação das narrativas, percebe-se em Saramago a representação de um tempo presente, em sua complexidade social e política. O espaço representado é o da própria Península Ibérica em assombrosa transformação. Já em João Ubaldo, o tempo representado está associado a um passado colonial, com suas instituições (escravidão, aculturação indígena, religião inquisitória, etc.) e seus costumes. Quanto ao espaço, também uma ilha que existe ou não e que dá condições ao necessário isolamento da construção utópica. A Ilha do Pavão é representada como alegoria do Brasil, mas está localizada no recôncavo baiano e, por decorrência, é parte da Bahia, que é parte do Brasil.

Há também similaridade no protagonismo múltiplo projetado para ambas as narrativas. Também em $O$ feitiço da Ilha do Pavão um grupo heterogêneo de heróis sai em peregrinação pela ilha, à procura de solução para os problemas da comunidade. Balduíno, lo Pepeu, Capitão Cavalo, Degredada, Hans e Crescência são aparentados ao grupo de portugueses e espanhóis que protagoniza $A$ jangada de pedra, não só pela heterogeneidade do grupo, mas pela aura de misticismo e bruxaria que acolhe parte de seus integrantes. É também em meio ao grupo que surgem os ideais de uma vida mais humana, mais livre e mais justa.

\section{Utopia e crise}

Para Fredric Jameson (2006), o surgimento das grandes utopias vincula-se a "períodos de grande fermentação social, mas aparentemente sem leme, sem força motriz nem direção", algo que encontra reflexo em ambos os romances analisados. No caso de $\boldsymbol{A}$ jangada de pedra, uma crise mais evidente, uma metáfora da própria (perda da) identidade nacional. Saramago parte de um contexto histórico adverso para os portugueses e constrói a fábula de um novo destino para a nação, um contexto, como vimos, trans-ibérico, aproximando Portugal e Espanha das maiores concentrações de falantes de língua espanhola e portuguesa - não por coincidência suas principais ex-colônias.

Já a narrativa de João Ubaldo é centrada nos dilemas históricos da formação da nação brasileira. Qual a organização política mais adequada? As populações indígenas devem ter acesso à cidadania? Como enfrentar a mácula da escravidão? Como conviver com o falso moralismo religioso? São essas algumas das grandes crises enfrentadas pela utopia da Ilha do Pavão. Por ocasião do lançamento de $O$ feitiço, João Ubaldo assim se refere aos propósitos da obra: "Um Brasil meio maluco, um Brasil afastado do Brasil, mas brasileiro. Eu quis fazer uma utopia. Uma utopia relativa a um lugar que não existe. Fazer um cadinho de Brasil onde o Brasil se desenvolvesse de forma diferente."4

Diferente, porém não necessariamente utópica, no sentido de encontrar e propor a solução para a "raiz de todo o mal" (JAMESON 2006, p. 160).

4

Revista CULT. №. 6, janeiro de 1998, p. 32-39. 


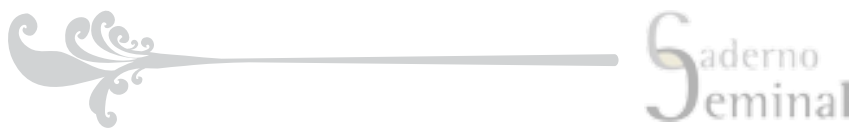

\section{Utopia e ideologia}

Quais seriam as utopias subjacentes às narrativas? Para Jameson, a utopia está sujeita a duas formas principais de análise: uma causal, ou diacrônica, a outra institucional, ou sincrônica. Na abordagem sincrônica, está em causa a utopia como construção, já abordada em parte. Já na abordagem diacrônica, importa definir qual a "raiz de todo o mal" que a utopia deve combater. No caso de $A$ jangada de pedra, Saramago contrapõe à utopia da União Europeia sua própria utopia, a re-situação dos países ibéricos numa "bacia cultural atlântica" (ROCHA, 2009).

Em O feitiço da Ilha do Pavão, a raiz de todo mal está na escravidão, na tirania dos líderes e na intromissão da igreja no mundo laico. No combate a essas forças, parece não ser possível dispensar o uso da força e o derramamento de sangue. Eis então que se revela qual o feitiço da Ilha: uma porta para os futuros possíveis que, enquanto acessada por um dos aventureiros, paralisa o tempo em todo o território da ilha. Os protagonistas têm assim a oportunidade de fazer parar o tempo, quando os desdobramentos da ação Ihes parecem indesejáveis, e de escolher uma "nova versão" para o futuro entre as versões que se Ihes apresentam.

Subjaz à construção utópica, em ambos os romances, um ideário humanista, de valorização dos direitos humanos e de condenação ao acúmulo material. Ao delimitarem, cada qual ao seu modo, a "raiz de todo mal" em torno dessas questões, os autores reafirmam seus compromissos políticos de enfrentamento da desigualdade e da injustiça social.

\section{Utopia e negatividade}

Em Jameson (2006), o que caracteriza a utopia como essencialmente negativa é nossa incapacidade de imaginar um mundo melhor, revelando o "fechamento ideológico do sistema em que estamos, de algum modo, cercados e confinados." Por isso não raro as utopias desembocam em seus contrários. Não há qualquer segurança, por exemplo, no futuro reservado para a ilha ibérica, isolada dos continentes em pleno Atlântico. Ao final do romance, a vara de negrilho espetada sobre o túmulo de Pedro Orce "talvez floresça" no ano seguinte. No desfecho de O Feitiço da Ilha do Pavão o desencanto é também evidente. Tendo em mãos o próprio futuro, podendo, talvez, aspirar à perfeição, os heróis optam pelo menor dos males possível, algo que restabeleça o equilíbrio, sem alterar radicalmente as relações de poder na ilha:

Muito bem, o quilombo viria abaixo por sua própria vontade, D. Afonso Jorge seria no máximo rei de suas mulheres, as vilas escolheriam seus próprios destinos, provavelmente tudo iria acontecer como já queria a maioria, Borges Lustosa seria duque de São João, não mais da ilha, padre Tertuliano seria grão-bispo também de São João e, mais tarde, talvez de toda a ilha, até 
porque, em seu papado, padres e freiras poderiam continuar consagrandose à vida religiosa, mas casando-se ao bel-prazer. E Balduíno, detentor de segredos básicos dos homens e da Natureza, continuaria como despachador, sempre influindo aqui e acolá e desfrutando da vida que sempre quis ter, com os outros índios também podendo morar nas vilas. (RIBEIRO, 2011, p. 263)

\section{Conclusão}

Diante das acanhadas utopias representadas em ambas as obras, é interessante retornar ao primeiro parágrafo do texto "A política da utopia", de Fredric Jameson, que vimos seguindo até aqui:

A utopia parece ser a demonstração de um daqueles raros fenômenos cujo conceito é indistinguível de sua realidade, cuja ontologia coincide com sua representação. Essa entidade peculiar ainda tem função social? Se não a tiver mais, talvez a explicação esteja naquela extraordinária dissociação histórica em dois mundos distintos que caracteriza a globalização de hoje. Num desses mundos, a desintegração do social é tão absoluta - miséria, pobreza, desemprego, fome, corrupção, violência e morte - que os elaboradíssimos esquemas sociais dos pensadores utópicos tornam-se tão frívolos quanto irrelevantes. No outro, a riqueza sem paralelo, a produção computadorizada, as descobertas médicas e científicas inimagináveis há um século, além de uma variedade interminável de prazeres comerciais e culturais, parecem ter tornado a fantasia e a especulação utópicas tão tediosas e antiquadas quanto as narrativas pré-tecnológicas de vôos espaciais. (JAMESON, 2006, p. 159)

Esses dois mundos de que nos fala Jameson convivem e se confrontam em vários momentos em $A$ Jangada de Pedra. Convivem e também se separam, com a fuga das elites para o Continente. Em $O$ feitiço da Ilha do Pavão temos a gênese desses mundos, ainda sob a influência de uma tecnologia incipiente. Nos dois romances, o "salto utópico", isto é, a passagem para a nova realidade, só é possível mediante a ação do fantástico, do sobrenatural, e mesmo assim resulta em formulações que estão distantes da ideia original da utopia. Talvez, de fato, ela não seja mais possível, ou talvez ela tenha se tornado inútil. Ainda assim, segundo Eduardo Galeano, que debateu com Saramago no Fórum Social Mundial em 2005, a utopia servirá para algo:

\section{Ventana sobre la utopía}

Ella está en el horizonte - dice Fernando Birri -. Me acerco dos passos, ella se aleja dos passos. Camino diez pasos y el horizonte se corre diez passos más allá. Por mucho que yo camine, nunca la alcanzaré. ¿Para que sirve la utopía? Para eso sirve: para caminar. ${ }^{5}$

5 GALEANO, Eduardo H. Las palabras andantes. México: Siglo Veintiuno, 1993. 


\title{
NATION AND UTOPIA IN A JANGADA DE PEDRA AND O FEITIÇO DA ILHA DO PAVÃO
}

\begin{abstract}
:
This paper proposes a comparative reading about the topics "nation" and "utopia" in two contemporary romances of portuguese language: $\boldsymbol{A}$ jangada de pedra (1986), by Jose Saramago and O feitiço da Ilha do Pavão (1997), by João Ubaldo Ribeiro. The analysis is based on Fredric Jameson's concepts on utopia in postmodernity, and the approach between utopia and the concept of nation as "imagined community," by Benedict Anderson. The conclusion points out that, even resorting to the fantastic, the supernatural, the utopias of Saramago and João Ubaldo are timid, and that, as Jameson suggests, perhaps there are no more space for utopia nowadays.
\end{abstract}

\section{KEYWORDS:}

Nation; utopia; José Saramago; João Ubaldo Ribeiro; Fredric Jameson.

\section{REFERÊNCIAS}

ANDERSON, Benedict. Comunidades imaginadas. Trad. Denise Bottman. São Paulo: Companhia das Letras, 2008..

ARANTES, Paulo. "Nação em reflexão". In: ABDALA Jr., Benjamin e CARA, Salete de Almeida (orgs.). Moderno de nascença. Figurações críticas do Brasil. São Paulo: Boitempo, 2006. p. 27-45.

BERRIEL, Carlos Eduardo Ornelas et. all. Proposta de criação do U-TOPOS - Centro de Estudos sobre Utopia IEL-UNICAMP. Campinas: IEL-UNICAMP, 2008. Disponível em: http://www.iel.unicamp.br/pesquisa/arquivos/Centro_de_ Pesquisa_sobre_Utopia_U-TOPOS.pdf. Acesso em: 05/4/2012.

CALBUCCI, Eduardo. Saramago: Um roteiro para os romances. São Paulo: Ateliê, 1999.

GUILLÉN, Claudio. Entre lo uno y lo diverso. Introducción a la literatura comparada. Barcelona: Tusquets, 2005..

JAMESON, Fredric. "A política da utopia". In: SADER, Emir (org.) Contragolpes. Seleção de artigos da New Left Review. Trad: Beatriz Medina. São Paulo: Boitempo, 2006. p. 159-176. Disponível em: http://newleftreview.org/?page=fl;pdflang=pt. Acesso em: 05/4/2012. 


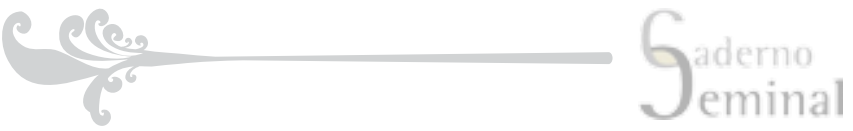

LEITE, Ligia Chiappini Moraes. O foco narrativo (ou A polêmica em torno da ilusão). São Paulo: Ática, 1985. (Série Princípios).

LOGAN, George M.; ADAMS, Robert M. "Introdução". In: MORE, Thomas. Utopia. Trad. Jefferson Luiz Camargo e Marcelo Brandão Cipolla. 3a ed. São Paulo: Martins Fontes, 2009. p. XV-XLVII.

MARTINS, Lourdes Câncio. "Reconfigurações da utopia na ficção pós-moderna".

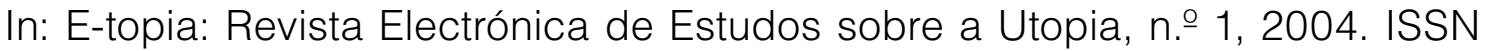
1645-958X. Disponível em http://www.letras.up.pt/upi/utopiasportuguesas/etopia/revista.htm. Acesso em: 05/4/2012.

PENHA, Gisela Maria de Lima Braga. (2004) "A (Im)Provável Gênese TransIbérica em a Jangada de pedra, de José Saramago", Polifonia: Revista do programa de pós-graduação em estudos de linguagem-mestrado da UFMT, № 9. ISSN 0104-687X. Disponível em: http://cpd1.ufmt.br/meel/polifonia.php?cod=3 .Acesso em: 05/4/2012.

RIBEIRO, João Ubaldo. O feitiço da Ilha do Pavão. $2^{a}$ Ed. Rio de Janeiro: Objetiva, 2011.

ROCHA, Iraci Simões da Rocha. (2009) "Utopia e práxis: esperança e ação em Saramago e Pepetela". In: Recôncavos: Revista do Centro de Artes, Humanidades e Letras da UFRB. vol. 3 (1). ISSN 1983-5078. Disponível em: http://www.ufrb. edu.br/reconcavos/edicoes/n03/pdf/Iraci.pdf . Acesso em: 05/4/2012.

SARAMAGO, José. (1990) "Mi iberismo" (Prólogo). In: MOLINA, CÉSAR ANTÓNIO, Sobre el iberismo y otros escritos de literatura portuguesa. Madrid, Akal/Bolsillo, 1990. Disponível em: http://hispanismo.org/politica-y-sociedad/2179-josesaramago-mi-iberismo.html. Acesso em: 05/4/2012.

Portugal - fim de milênio, princípio de quê?,1996. Disponível em: http:// josesaramago.org/6447.html Acesso em: 05/4/2012. de Bolso).

. A jangada de pedra. São Paulo: Companhia das Letras, 2006 (Companhia 